\title{
Influence of Organic Peroxide on the Performance of Maleic Anhydride Coated Cellulose Fiber-Filled Thermoplastic Composites
}

\author{
D. Maldas and B. V. KoKta \\ Centre de Recherche en Pâtes et Papiers, Université du Québec à Trois-Rivières, \\ C.P. 500, Trois-Rivières, Québec, Canada, G9A 5 H7
}

(Received February 1, 1991)

\begin{abstract}
This paper deals with the mechanical properties of surface modified cellulose fiber-filled thermoplastic composites. The surface modifications were carried out by using maleic anhydride (MA) as a coupling agent. MA-coated fibers provided a positive response with regard to the mechanical properties of composites. On the whole, these properties improved compared to those of virgin polymers. The influence of two organic peroxides, e.g., benzoyl peroxide (BPO) and dicumyl peroxide (DCP), on the properties of composites was also studied. The concentration of MA, initiators and wood fibers plays an important role on the mechanical properties of the composites, e.g., properties improved along with the rise in concentration of each of the above, up to a certain limit, and then decreased at higher concentrations. Moreover, properties varied with the change in type of cellulose fiber, e.g., CTMP aspen, sawdust aspen and nutshell, and nature of thermolastic, e.g., polyethylene and polystyrene. As far as the mechanical properties of the composites were concerned, DCP was believed to be a better initiator.

KEY WORDS Organic Peroxide / Maleic Anhydride / Wood Fiber / Graft

Copolymerization / Surface Modification / Thermoplastic Composites /

Interfacial Contact / Adhesion / Coupling Reaction / Mechanical Properties /
\end{abstract}

Fillers, particularly cellulosics, have always played an important role in the plastics industry. ${ }^{1}$ In fact, the demand for unmodified fillers while reduce costs, but contribute little to improve the properties of plastics, has risen only marginally in recent years. ${ }^{2}$ However, with the selection of proper compounding methods, treatment and design, natural fiber-filled composites could be promising in many fields. ${ }^{3-5}$ In addition, modifying the filler's surface by selecting suitable coupling agents in order to improve the compatibility level, enhances filler use. ${ }^{6-15}$ Moreover, a higher filler concentration can also be used with improved physical and mechanical properties.

Among the various coupling agents which were used to modify the surface of cellulosic fibers, maleic anhydride (MA) has revealed itself to be an efficient one. ${ }^{15-20}$ According to the literature, the presence of an organic peroxide is essential during the coating treatment of cellulosic fibers with maleic anhydride. ${ }^{15}$ Moreover, inaddition to the concentration of MA, the type and concentration of organic peroxides are also controlling factors in the performance of modified fillers, because the relative heat sensitivity of each type of peroxide differs a great deal. ${ }^{21}$

In the current study, the efficiency of two organic peroxides, e.g., benzoyl peroxide (BPO) and dicumyl peroxide (DCP), was compared by evaluating the mechanical properties of MA-modified nutshell and wood fiber-filled polyethylene and polystyrene composites. The effect of the concentration of MA and peroxides was also taken into account. 


\section{MATERIALS}

\section{Thermoplastics}

The thermoplastics used were high-impact polystyrene (PS 525) supplied by Polysar Limited, Sarnia, Ontario, Canada. High density polyethylene (HRSN 8907) [HDPE] was supplied by Novacor Co., Calgary, Alberta, Canada.

\section{Fillers}

Hardwood aspen was used in the form of wood flour (sawdust) and chemithermomechanical pulp (CTMP). CTMP was prepared in a Sund Defibrator under the same conditions as described in ref 12. CTMP aspen pulp and chips used to make sawdust were dried in an air-circulating oven at $55^{\circ} \mathrm{C}$ for $48 \mathrm{~h}$, and then ground to a mesh size 60 mixture: $60.5 \%$, mesh $60 ; 20.2 \%$, mesh $80 ; 15.5 \%$, mesh 100 ; and $3.5 \%$, mesh 200, with a Granu Grinder, C. W. Brabender Instruments Inc., U.S.A.

Blends of pecan shell and peanut hull flour of mesh size 200 was supplied by Southeastern Reduction Co., Valdosta, Georgia, U.S.A. The fillers were oven-dried by circulating air at $55^{\circ} \mathrm{C}$ for 5-7 days.

\section{Coupling Agents and Initiator}

Maleic anhydride (MA), benzoyl peroxide (BPO), and dicumyl peroxide (DCP) were supplied by Anachemia, Montréal, Canada.

\section{EXPERIMENTAL}

\section{Surface Modification}

Fillers were surface modified with HDPE/PS 525 which is the same as the one used in composites ( $5 \%$ by weight of filler), maleic anhydride ( $0 \%$ to $3 \%$ by weight of filler) and benzoyl peroxide (BPO)/dicumyl peroxide (DCP) $(0 \%$ to $1 \%$ by weight of filler) with the help of a Laboratory Roll Mill (C. W. Brabender, Model No. 065) at $170^{\circ} \mathrm{C}$ for $5 \mathrm{~min}$. The surface modified fillers were passed through a screen of mesh size 20 in a Granu Grinder, C. W. Brabender Instruments, Inc.

\section{Preparation of Composities}

A $25 \mathrm{~g}$ mixture of polymer and surface modified filler $(10-30 \%$ by weight of composites) were mixed in the roll mill at $170^{\circ} \mathrm{C}$. After mixing 5-10 times, the mixtures were allowed to cool to room temperature, and then ground once more to mesh size 20 . The mixtures were then molded into shoulder-shaped test specimens (ASTM D-638, Type V). Standard molding conditions for polystyrene-based composites were: temperature, $175^{\circ} \mathrm{C}$; pressure during heating and cooling, $3.8 \mathrm{MPa}$; heating time, $20 \mathrm{~min}$; cooling time, $10 \mathrm{~min}$, and for polyethylene-based composites the molding conditions were: temperature, $155^{\circ} \mathrm{C}$; pressure during heating and cooling, $4.34 \mathrm{MPa}$; heating time, $5 \mathrm{~min}$; cooling time, $10 \mathrm{~min}$. Width and thickness of each specimen were measured with the help of a micrometer.

\section{Mechanical Tests}

The mechanical properties (e.g., modulus at $0.1 \%$ strain, tensile strength at yield point and corresponding elongation and energy) of all the samples were measured with an Instron Tester (Model 4201) following ASTM D-638. A standard general Tensile Test Program method, called "PLA 10," was used, and the mechanical properties were automatically calculated with a HP-86B computer. The strain rate was $1.5 \mathrm{~mm} \mathrm{~min}^{-1}$ for polystyrene-based composites and $10 \mathrm{~mm} \mathrm{~min}^{-1}$ for polyethylene-based composites. Unnotched Izod impact strength was tested following ASTM D-256 with an Impact Tester (Model TMI, No. 43-01) supplied by Testing Machines Inc., U.S.A. The samples were tested after conditioning at $23 \pm 0.5^{\circ} \mathrm{C}$ and $50 \%$ R.H. for at least $18 \mathrm{~h}$ in a controlled atmosphere. The statistical average of the measurements of at least 5 specimens was taken to obtain a reliable average and standard deviation. The coefficients of variation for the mechanical properties vary from $2.5-8.5 \%$. 


\section{RESULTS AND DISCUSSION}

Figures $1-5$ show varying mechanical properties according to the concentration of maleic anhydride and nature of peroxide for nutshell-filled polyethylene and polystyrene composites. Fiber concentration varied from

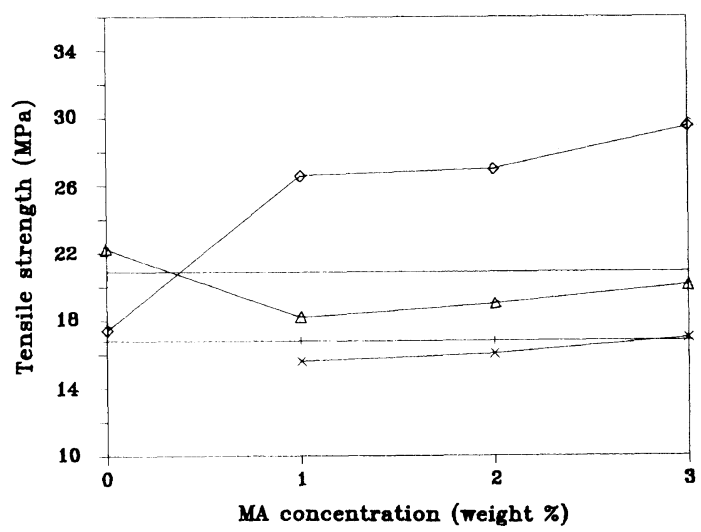

Figure 1. Variation of tensile strength with the concentration of maleic anhydride (MA) and nature of peroxide for polyethylene (HDPE)/polystyrene (PS 525)nutshell composites. (-), HDPE (virgin); (+), polystyrene PS 525 (virgin); $(\triangle), \mathrm{HDPE}+10 \mathrm{wt} \%$ nutshell $+1 \mathrm{wt} \%$ BPO; $(\diamond)$, HDPE $+30 w t \%$ nutshell $+1 w t \% D C P O$ and $(x)$, PS $525+20 w t \%$ nutshell $+1 w t \%$ BPO.

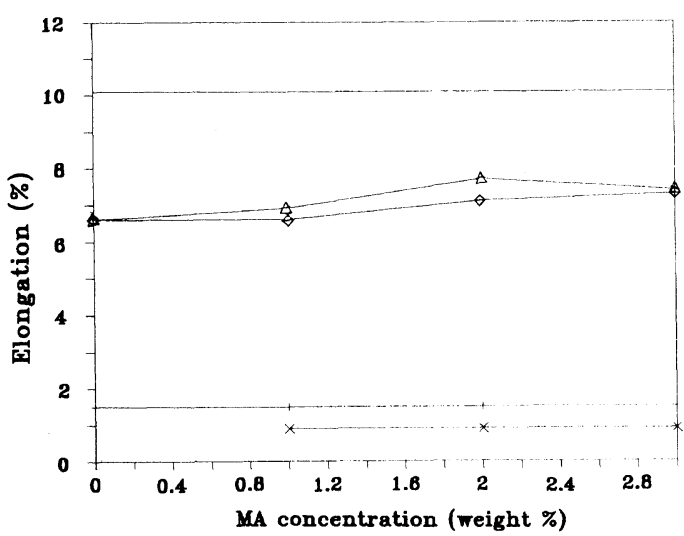

Figure 2. Variation of elongation with the concentration of maleic anhydride (MA) and nature of peroxide for polyethylene (HDPE)/polystyrene (PS 525)-nutshell composites. (-), HDPE (virgin); (+), polystyrene PS 525 (virgin); $(\diamond), \mathrm{HDPE}+10 \mathrm{wt} \%$ nutshell $+1 \mathrm{wt} \% \mathrm{BPO} ; \triangle)$, HDPE $+10 w t \%$ nutshell $+1 w t \%$ DCPO and $(x)$, PS $525+10 w t \%$ nutshell $+1 w t \%$ BPO.
$10 \mathrm{wt} \%$ to $30 \mathrm{wt} \%$. However, in the figures, only the concentrations of fiber where best results were obtained are taken into account. Figure 1 reveals that tensile strength for both peroxides increase gradually with the increase of the MA concentration from $1 \mathrm{wt} \%$ to $3 \mathrm{wt} \%$. For PE-based composites, the tensile strength

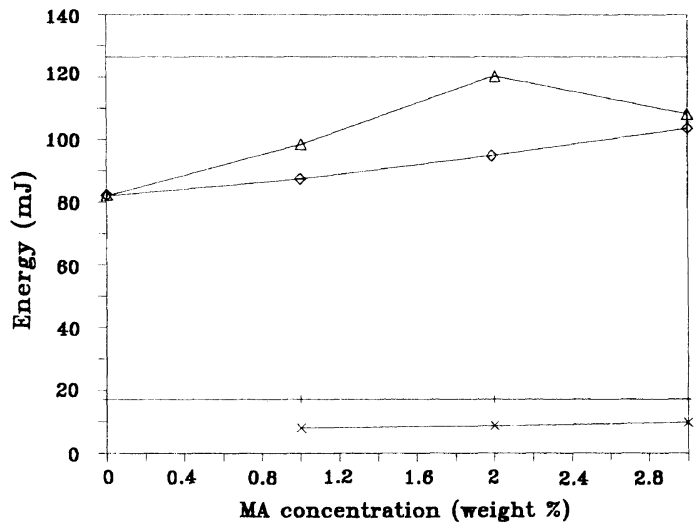

Figure 3. Variation of energy with the concentration of maleic anhydride (MA) and nature of peroxide for polyethylene (HDPE)/polystyrene (PS 525)-nutshell composites. (-), HDPE (virgin); (+), polystyrene PS 525 (virgin); $(\diamond), \mathrm{HDPE}+10 \mathrm{wt} \%$ nutshell $+1 \mathrm{wt} \% \mathrm{BPO} ;(\triangle)$, HDPE $+10 w t \%$ nutshell $+1 w t \%$ DCPO and $(x)$, PS $525+10 w t \%$ nutshell $+1 w t \%$ BPO.

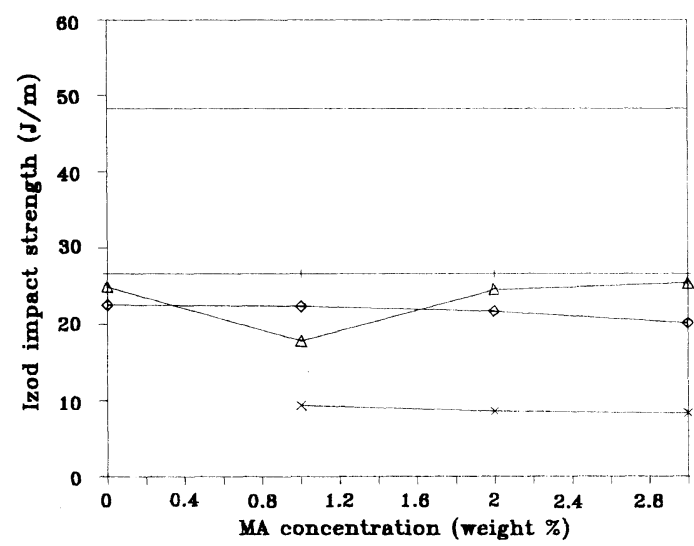

Figure 4. Variation of Izod impact strength with the concentration of maleic anhydride (MA) and nature of peroxide for polyethylene (HDPE)/polystyrene (PS 525)nutshell composites. (-), HDPE (virgin); (+), polystyrene PS 525 (virgin); $(\diamond)$, HDPE $+20 \mathrm{wt} \%$ nutshell $+1 \mathrm{wt} \%$ BPO; $(\triangle), \quad$ HDPE $+10 w t \% 10 w t \%$ nutshell $+1 w t \%$ DCPO and $(\times)$, PS $525+10 w t \%$ nutshell $+1 w t \%$ BPO. 
value of composites is less than that of virgin polymers and, for PS-based composites, the same property followed a similar trend, except

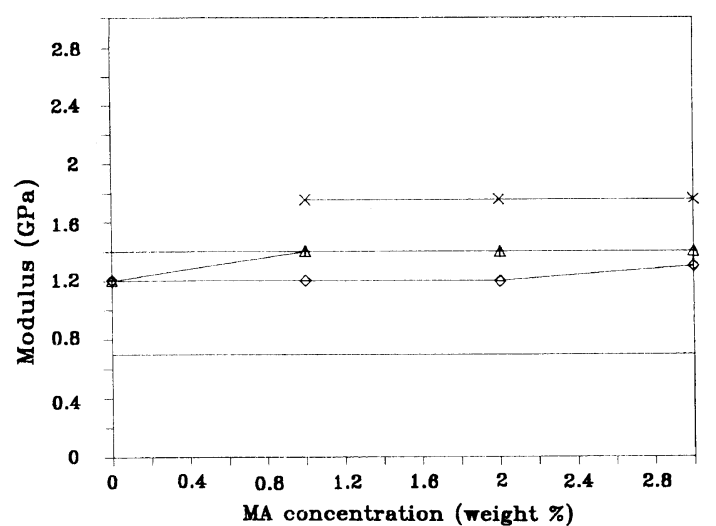

Figure 5. Variation of modulus with the concentration of maleic anhydride (MA) and nature of peroxide for polyethylene (HDPE)/prolystyrene (PS 525)-nutshell composites. (-), HDPE (virgin); (+), polystyrene PS 525 (virgin); $(\diamond), \mathrm{HDPE}+30 \mathrm{wt} \%$ nutshell $+1 \mathrm{wt} \% \mathrm{BPO} ; \triangle)$, HDPE $+30 w t \%$ nutshell $+1 w t \%$ DCPO and $(x)$, PS $525+30 w t \%$ nutshell $+1 w t \%$ BPO. at higher concentrations of MA. However, the tensile strength value of PE-based composites, particularly when DCP was used as an initiator, improved compared to that of virgin $\mathrm{PE}$ and of composites in which BPO was used. It is obvious from this figure that when DCP is present, strength improves until a higher level of fiber is reached, e.g., $30 \mathrm{wt} \%$, while for BPO the optimum concentration of fiber is only $10 \mathrm{wt} \%$.

Both elongation and energy (Figures 2 and 3 ) of the composites indicate that their values diminished compared to those of virgin polymers. For PE-based composites, these properties edge up with the increase in the concentration. For PS-based composites, they remain constant with the change in the MA concentration. DCP performs better for elongation and energy: maximum improvement was noticed at $2 \mathrm{wt} \%$ of MA. Figure 4 reveals that Izod impact strength for both PE and PS-based composites has practically no

Table I. Effect of the nature of peroxide on the mechanical properties of various cellulose fiber-filled thermoplastic composites ${ }^{a}$

\begin{tabular}{|c|c|c|c|c|c|c|c|c|c|c|}
\hline \multirow{4}{*}{$\begin{array}{l}\text { Polymer/ } \\
\text { fiber }\end{array}$} & \multirow{4}{*}{$\begin{array}{l}\text { Nature of } \\
\text { peroxide }\end{array}$} & \multirow{2}{*}{\multicolumn{3}{|c|}{$\frac{\text { Tensile strength }}{\mathrm{MPa}}$}} & \multirow{2}{*}{\multicolumn{3}{|c|}{$\frac{\text { Modulus }}{\mathrm{GPa}}$}} & \multirow{2}{*}{\multicolumn{3}{|c|}{$\frac{\text { Inpact strength }}{\mathrm{J} \mathrm{m}^{-1}}$}} \\
\hline & & & & & & & & & & \\
\hline & & 10 & & 30 & 10 & 20 & 30 & 10 & 20 & 30 \\
\hline & & \multicolumn{3}{|c|}{$w t \%$ of fiber } & \multicolumn{3}{|c|}{ wt $\%$ of fiber } & \multicolumn{3}{|c|}{ wt $\%$ of fiber } \\
\hline HDPE & - & \multicolumn{3}{|c|}{20.9} & \multicolumn{3}{|c|}{0.7} & \multicolumn{3}{|c|}{47.8} \\
\hline N.S. & - & 22.2 & 20.1 & 17.4 & 1.1 & 1.1 & 1.2 & 23.4 & 21.0 & 18.6 \\
\hline N.S. & B & 20.1 & 16.7 & 15.8 & 1.0 & 1.1 & 1.3 & 16.9 & 18.5 & 20.2 \\
\hline N.S. & $\mathrm{C}$ & 25.8 & 28.1 & 29.5 & 1.1 & 1.3 & 1.4 & 24.2 & 20.5 & 19.4 \\
\hline CTMP-A & B & 23.0 & 31.0 & 38.5 & 1.1 & 1.6 & 2.1 & 26.5 & 31.4 & 31.2 \\
\hline CTMP-A & $\mathrm{C}$ & 26.6 & 30.7 & 39.0 & 1.5 & 1.7 & 2.2 & 29.1 & 30.5 & 34.0 \\
\hline S.D.-A & B & 20.3 & 22.6 & 26.9 & 1.2 & 1.6 & 2.0 & 27.6 & 25.5 & 24.3 \\
\hline S.D.-A & $\mathrm{C}$ & 18.8 & 25.6 & 19.6 & 1.4 & 1.7 & 2.0 & 33.1 & 25.6 & 21.0 \\
\hline PS 525 & - & \multicolumn{3}{|c|}{16.8} & \multicolumn{3}{|c|}{1.4} & \multicolumn{3}{|c|}{25.2} \\
\hline N.S. & B & 16.6 & 17.7 & 16.1 & 1.6 & 1.7 & 1.8 & 8.4 & 6.6 & 6.0 \\
\hline N.S. & $\mathrm{C}$ & 16.3 & 17.4 & 15.9 & 1.5 & 1.6 & 1.9 & 10.7 & 7.2 & 6.0 \\
\hline CTMP-A & B & 19.6 & 22.2 & 19.2 & 1.8 & 1.9 & 2.0 & 12.9 & 10.0 & 6.2 \\
\hline CTMP-A & $\mathrm{C}$ & 19.6 & 23.1 & 19.4 & 1.8 & 2.0 & 2.2 & 10.4 & 9.0 & 8.4 \\
\hline S.D.-A & B & 17.8 & 18.9 & 18.5 & 1.7 & 1.9 & 2.0 & 8.8 & 10.1 & 9.4 \\
\hline S.D.-A & $\mathrm{C}$ & 18.5 & 19.3 & 20.9 & 1.7 & 1.9 & 2.2 & 10.8 & 11.3 & 10.4 \\
\hline
\end{tabular}

a N.S., nutshell; S.D., sawdust; A, aspen; B, benzoyl peroxide; C, dicumyl peorixide.

Fibers were coated with polymer (same as in composites), $5 \mathrm{wt} \%$ by weight of fiber $+\mathrm{MA}, 3 \mathrm{wt} \%$ by weight of fiber + peroxide, $1 \mathrm{wt} \%$ by weight of fiber. 
Table II. Effect of the nature of peroxide on the mechanical properties of various cellulose fiver-filled thermoplastic composites ${ }^{a}$

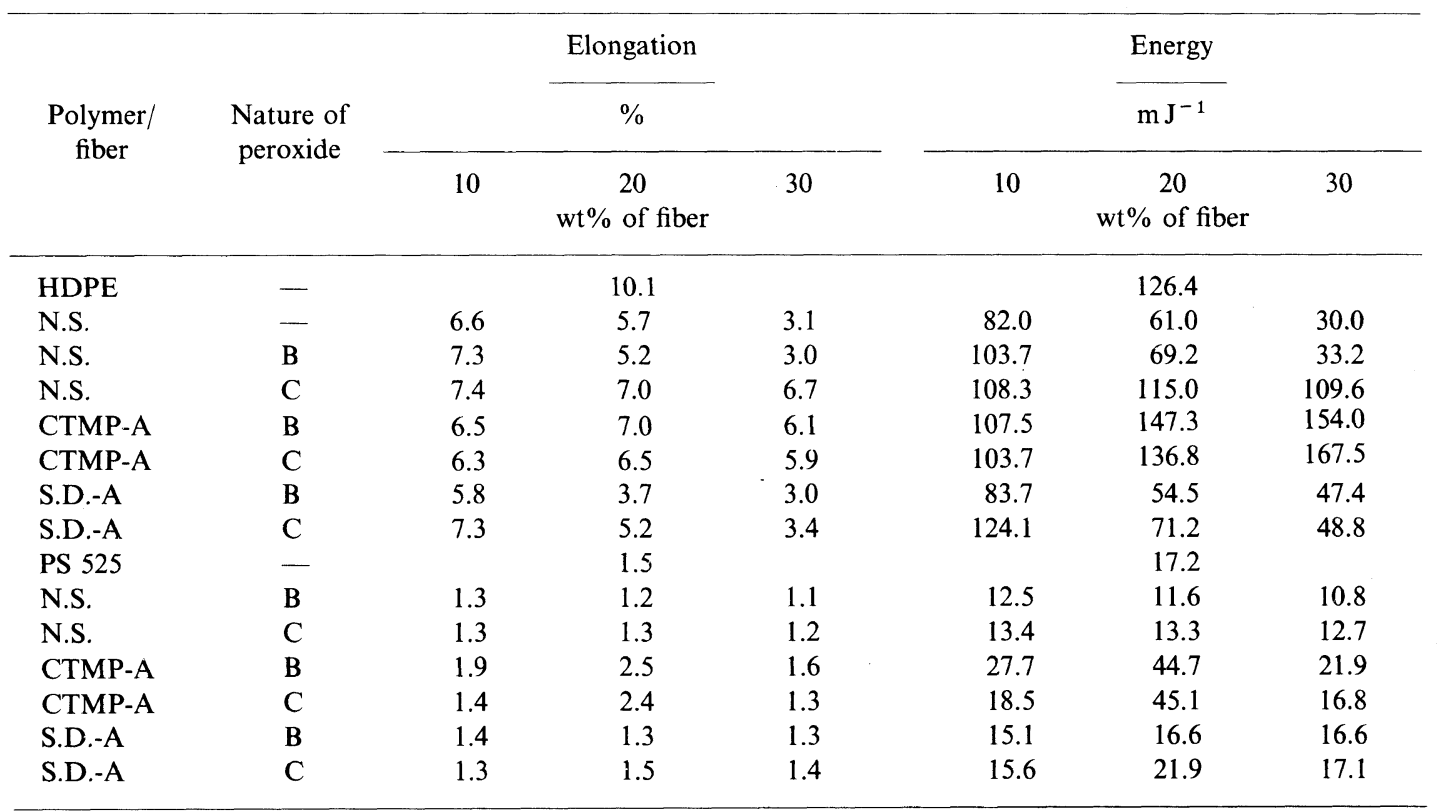

a N.S., nutshell; S. D., sawdust; A, aspen; B, benzoyl peroxide; C, dicumyl peroxide.

Fibers were coated with polymer (same as in composites), $5 \mathrm{wt} \%$ by weight of fiber $+\mathrm{MA}, 3 \mathrm{wt} \%$ by weight of fiber + peroxide, $1 \mathrm{wt} \%$ by weight of fiber.

effect on the concentration of MA when BPO is used as the initiator. But when DCP is used, impact strength increased with the increase of MA concentration, especially at higher concentrations of MA. Compared to virgin polymers, the impact strength of the composites decreases, through the same property improves for DCP by contrast to BPO. Modulus (Figure 5) of composites remain constant when the concentration of MA varies. Modulus of composites for DCP also rank better than modulus for BPO.

Tables I and II compare the mechanical properties of both PE and PS composites filled with 3\% MA coated cellulose fibers (e.g., nutshell, CTMP aspen and sawdust aspen). The effect of $1 \%$ DCP and $1 \%$ BPO on the mechanical properties of composites was also taken account in the study. It is obvious from these tables that properties change according to filler content. Optimum fiber levels where maximum improvement in properties takes place change with the nature of peroxide, polymer and fiber, and overall with the quality of the mechanical properties. For example, in comparison to virgin polymers, tensile strength for PE composites improve in most cases up to $30 \mathrm{wt} \%$ of fiber and very rarely up to $20 \mathrm{wt} \%$, whereas the same property for PS composites improves in most cases up to $20 \mathrm{wt} \%$ of fiber and very rarely up to $30 \mathrm{wt} \%$. Modulus always increases linearly following the concentration of fiber. The impact strength of the composites diminishes in comparison with that of virgin polymers. Impact strength of CTMP-filled PE composites for both DCP and BPO, and of nutshell-filled PE composites for only BPO increases up to $30 \mathrm{wt} \%$ of fiber, while the same property for the remaining cases decreased with the rise in fiber content. Likewise, a close study of PS-based composites reveals that, except for sawdust aspen-filled 
composites and for DCP, impact strength decreased with the increase of fiber content. Elongation of PE-based composites is always less than that of virgin polymer. Energy for the same composites follow more or less similar trends, except for CTMP-filled composites where the opposite is observed, i.e., it drives upwards with the upgrading in fiber content. The energy value exceeds that of unfilled polymer even at $20 \mathrm{wt} \%$ of fiber level. Both elongation and energy of nutshell-filled PS composites exhibit inferior results compared to those of virgin polystyrene, and decrease very slowly with added fiber content. For CTMP-filled PS composites, both elongation and energy improve with respect to unfilled polymer, up to $20 \mathrm{wt} \%$ of fiber level. Once again, for sawdust-filled composites, only energy improved up to $20 \mathrm{wt} \%$ when DCP was used as an initiator.

According to Tables I and II, DCP provided better performance. Concerning the tensile strength of PE composites, when one judges the effectiveness of all three fibers according to the highest property performance, it can be noticed that CTMP aspen $>$ nutshell $>$ sawdust aspen. CTMP aspen $\approx$ sawdust aspen $>$ nutshell for modulus of PS composites, while sawdust aspen $>$ nutshell $>$ CTMP aspen for elongation of PE composites. On the other hand, the order of performance for all other remaining cases are CTMP $>$ sawdust aspen $>$ nutshell.

Figures 6-10 illustrate the effect of the peroxide concentration on the mechanical properties of the composites. The tensile strength for PE composites increases with the concentration of DCP, and exceeds that of virgin PE. But for PS composites, the same property changes very slowly, or remains constant along with DCP concentration. When one examines the variation of tensile strength according to the concentration of BPO it is observed that it improves with rise in the concentration of BPO from $0.1 \%$ to $0.5 \%$ and, above this level, levels off and sometimes diminishes slightly. This is true for both polymer types while tensile strength improved in comparison to virgin polymers. Both elongation and energy (see Figures 7 and 8) exhibited an inferior behavior compared to those of virgin polymer, even when the

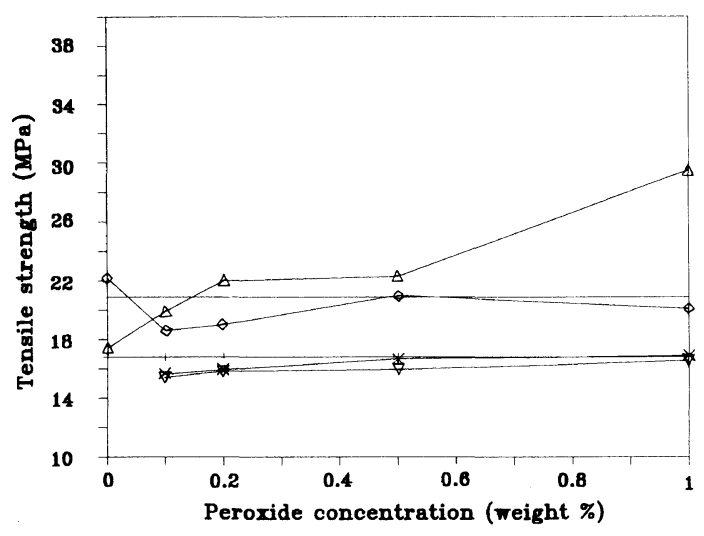

Figure 6. Variation of tensile strungth with the concentration and nature of peroxide for polyethylene (HDPE)/polystyrene (PS 525)-nutshell composites. (-), HDPE (virging); (+), polystyrene PS 525 (virgin); $(\diamond), \mathrm{HDPE}+10 \mathrm{wt} \%$ nutshell $+3 \mathrm{wt} \% \mathrm{MA}+\mathrm{BPO} ;(\triangle)$, HDPE + 30wt $\%$ nutshell + $3 w t \%$ MA + DCPO; $(x)$, PS $525+20 w t \%$ nutshell $+3 w t \%$ MA + BPO and $(\nabla)$, PS $525+20 w t \%$ nutshell $+3 w t \%$ MA + DCPO.

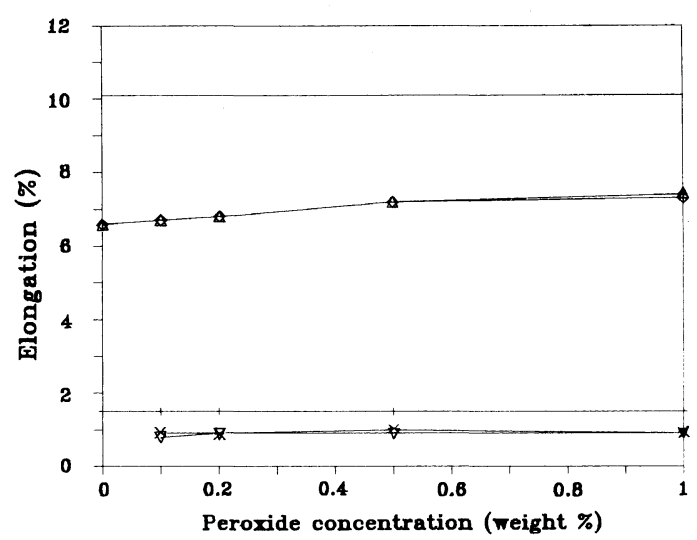

Figure 7. Variation of elongation with the concentration and nature of peroxide for polyethylene (HDPE)/polystyrene (PS 525)-nutshell composites. (-), HDPE (virgin); $(+)$, polystyrene PS 525 (virgin); $(\diamond), \mathrm{HDPE}+10 \mathrm{wt} \%$ nutshell $+3 \mathrm{wt} \% \mathrm{MA}+\mathrm{BPO} ;(\triangle), \mathrm{HDPE}+10 \mathrm{wt} \%$ nutshell $+3 w t \%$ MA + DCPO; $(x)$, PS $525+10 w t \%$ nutshell $+3 w t \%$ MA + BPO and $(\nabla)$, PS $525+10 w t \%$ nutshell + 3 wt $\%$ MA + DCPO. 


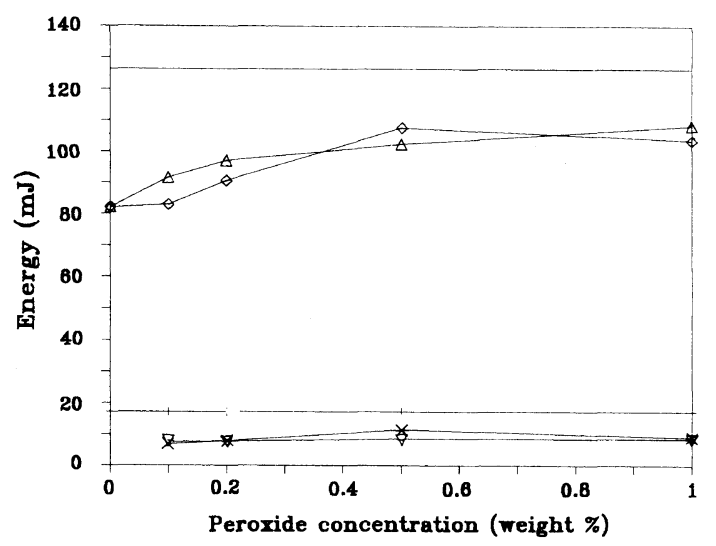

Figure 8. Variation of energy with the concentration and nature of peroxide for polyethylene (HDPE)/polystyrene (PS 525)-nutshell composites. (-), HDPE (virgin); (+), polystyrene PS 525 (virgin); $(\diamond), \quad \mathrm{HDPE}+10 \mathrm{wt} \%$ nutshell $+3 w \mathrm{t} \% \mathrm{MA}+\mathrm{BPO} ;(\triangle), \mathrm{HDPE}+10 \mathrm{wt} \%$ nutshell $+3 w t \%$ MA + DCPO; $(x)$, PS $525+10 w t \%$ nutshell $+3 w t \%$ MA + BPO and $(\nabla)$, PS $525+10 w t \%$ nutshell $+3 \mathrm{wt} \% \mathrm{MA}+\mathrm{DCPO}$.

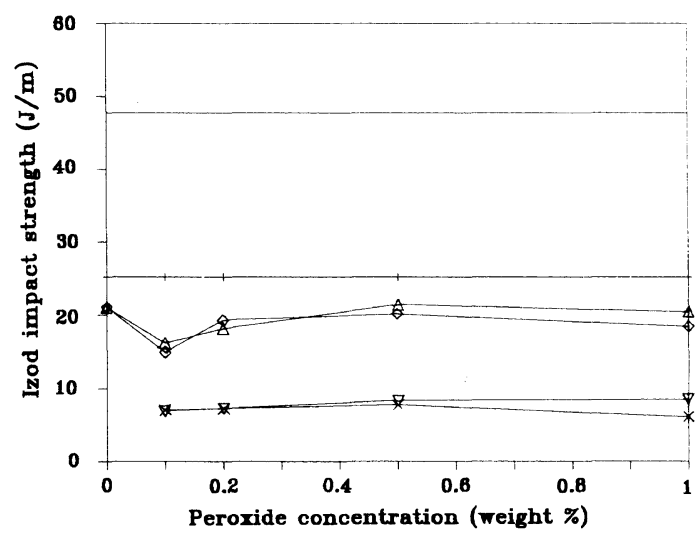

Figure 9. Variation of Izod impact strength with the concentration and nature of peroxide for polyethylene (HDPE)/polystyrene (PS 525)-nutshell composites. (-), HDPE (virgin); (+), polystyrene PS 525 (virgin); $(\diamond), \mathrm{HDPE}+20 \mathrm{wt} \%$ nutshell $+3 \mathrm{wt} \% \mathrm{MA}+\mathrm{BPO} ;(\triangle)$, HDPE + $20 w t \%$ nutshell $+3 w t \%$ MA + DCPO; $(x)$, PS $525+10 w \mathrm{t} \%$ nutshell $+3 \mathrm{wt} \% \mathrm{MA}+\mathrm{BPO}$ and $(\nabla)$, PS $525+10 w t \%$ nutshell $+3 w t \%$ MA + DCPO.

concentration of peroxide rose to $1 \mathrm{wt} \%$. Except for energy of PE-based composites, where properties changed with the concentration of peroxide, both elongation and energy remained unchanged with varying concentra-

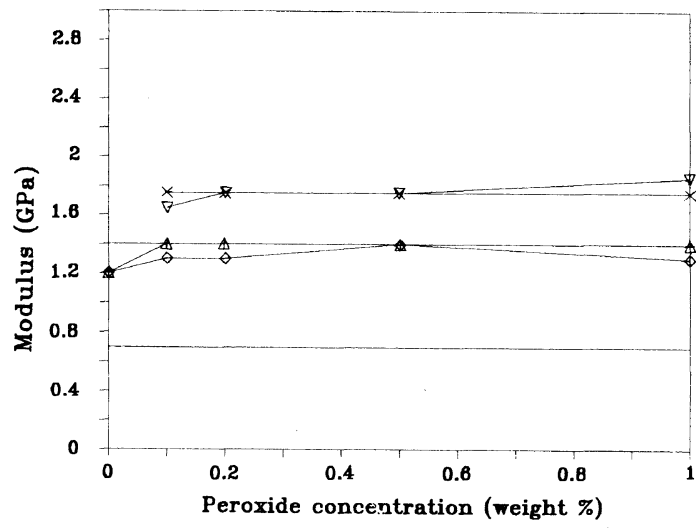

Figure 10. Variation of modulus with the concentration and nature of peroxide for polyethylene (HDPE)/polystyrene (PS 525)-nutshell composites. (-), HDPE (virgin); $(+)$, polystyrene PS 525 (virgin); $(\diamond), \mathrm{HDPE}+30 \mathrm{wt} \%$ nutshell $+3 \mathrm{wt} \%$ MA + BPO; $(\triangle)$, HDPE $+30 w t \%$ nutshell $+3 w t \%$ MA + DCPO; $(x)$, PS $525+30 w t \%$ nutshell $+3 w t \%$ MA + BPO and $(\nabla)$, PS $525+30 w t \%$ nutshell $+3 \mathrm{wt} \% \mathrm{MA}+\mathrm{DCPO}$.

tions of peroxide. As in the case of elongation and energy, Izod impact strength (see Figure 9) diminished and altered to a small extent with the change in the peroxide concentration. Here again DCP maintained its superiority over BPO. Modulus (see Figure 10) of composites exhibited better results than those of unfilled polymer and it changed only slightly, especially at much lower concentrations of peroxide; otherwise it remained constant. Moreover, DCP provided a slightly better performance than that of BPO.

The mechanical proeprties improved due to the addition of MA to the composites because the thermoplastic, cellulose and MA in the presence of an initiator form a block copolymer containing a succinic half ester bridge between cellulose and thermoplastic, e.g., polyethylene or polystyrene. ${ }^{15,16,18}$ Moreover, the $-\mathrm{OH}$ group of cellulose also has the ability of forming hydrogen bonds with the $-\mathrm{COOH}$ group of the MA segment. In this way, MA develops an overlapping interface area between fiber and polymer matrices. Prior grafting of the fiber with polymer and MA produces a soft film of hydrophobic material on the surface of 
the hydrophilic fiber. As a result, the phase separation between the two different matrices may reduce. In addition, strong fiber-fiber interaction due to intermolecular hydrogen bonding has also been diluted, which leads to better dispersion of the fibers. Mechanical properties improve independently of the concentration of MA because, with the rise in the concentration of MA in the composite, the possibility of forming an interfacial area increases.

The above-mentioned discussion indicates clearly that DCP ranks best as far as the mechanical properties of the composites are concerned. In the coupling reaction of cellulose, thermoplastic and MA, peroxide initiates the grafting of MA onto the thermoplastic matrix and/or crosslinking of macromolecules. The organic peroxides are characterised by the presence of "-O-O-" bonds which are dissociated by heat to generate free radicals $\left(\right.$ e.g., $\left.\mathrm{RO} \cdot+\cdot \mathrm{OR}^{\prime}\right){ }^{21}$ These free radicals are capable of triggering grafting and/or crosslinking reactions. The relative heat sensitivity or the decomposition rate for each type of peroxide differs greatly. However, the thermal activity of a peroxide is commonly expressed in terms of half life $\left(t_{1 / 2}\right)$ temperature. The $10 \mathrm{~h} t_{1 / 2}$ temperature for DCP and BPO are 117 and $73^{\circ} \mathrm{C}$, respectively. ${ }^{22}$ Therefore, the higher half life temperature of DCP contributes to the more stability of radicals and as a results, leads to better grafting performance compared to BPO at the compounding temperature. Incidentally, Callais et $a l .^{22}$ studied the effect of various organic peroxides on the graft modification of polyolefins with maleic anhydride. The samples were extruded at temperatures ranging from $160^{\circ} \mathrm{C}$ to $250^{\circ} \mathrm{C}$. They reported that the order of the effect of peroxides on grafting efficiency was DCP $\gg$ BPO. Our compounding temperature was $170-175^{\circ} \mathrm{C}$, and our experimental results also corroborate the fact that DCP is more efficient than BPO.

It is also obvious that the performance of three different fibers is not the same. In fact, the performance of cellulosics as the reinforcing fiber for plastics depends on their quality, e.g., fiber length, fiber-making technique, morphology, inherent physical and mechanical properties, origin, etc. ${ }^{23-25}$ Properties are also affected by the fiber-making process, even within the same species. Different pulping techniques offer various ways of separating fibers from the chips or raw materials, e.g., sawdust and nutshell particles were prepared by mechanical means, while both chemical and mechanical methods were used to prepare CTMP. As a result, fibers of CTMP are more separated and they are more flexible than the other two cellulose fibers. However, our experimental results are consistent with the fact that CTMP is without doubt the best pulp as far as mechanical properties of composites are concerned.

It is a well-established fact that fiber length is a critical parameter in the evaluation of the composites' properties. ${ }^{26}$ In the present study, both CTMP and sawdust were used with mesh size 60 , while nutshell required mesh size 200 . Therefore, it is also very difficult to compare the performance of cellulose fibers with different mesh sizes.

\section{CONCLUSIONS}

Coating treatments show some positve influence on the mechanical properties of the composites over that of uncoated fiber-filled composites and of virgin polymers. For a fixed peroxide concentration, properties improved along with the increase in the MA concentration until an optimum concentration was reached. Properties also varied with the nature and concentration of peroxides, fibers and thermoplastics. DCP ranked better than BPO. Among the three different fibers, CTMP seemed best with regard to mechanical properties. As far as cost is concerned, sawdust and nutshell were the most logical selections as fillers for thermoplastic composites after 
being submitted to surface modifications.

Acknowledgment. The authors wish to thank the FCAR and the CQVB of Québec for their financial support.

\section{REFERENCES}

1. B. M. Walker, "Handbook of Fillers for Plastics," H. S. Katz and J. V. Milewski, Ed., VNR Company, New York, N.Y., 1987, Chapter 20, p 420.

2. R. Leaversuch, Modern Plastics, May, 51 (1987).

3. R. H. Wehrenberg, II, $M E$, July, 54 (1981).

4. The Editor, Reinforced Plastics, 24(3), 66 (1980).

5. B. V. Kokta, R. Chen, C. Daneault, and J. Valade, Polym. Composites, 4(4), 229 (1983).

6. A. Y. Coran and R. Patel, U.S. Patent, 4323625 (April 6, 1982).

7. R. T. Woodhams, G. Thomas, and D. K. Rodgers, Polym. Eng. Sci., 24, 1166 (1984).

8. A. D. Beshay, B. V. Kokta, and C. Daneault, Polym. Composites, 6(4), 261 (1985).

9. P. Zadorecki and A. J. Michel, Polym. Composites, 10(2), 69 (1989).

10. H. Dalvag, C. Klason, and H.-E. Stromvall, Intern. J. Polymeric Mater., 11, 9 (1985).

11. M. H. Schneider and K. I. Brebner, Wood Sci. Technol., 19, 67 (1985).

12. D. Maldas, B. V. Kokta, R. G. Raj, and C. Daneault, Polymer, 29, 1255 (1988).
13. D. Maldas and V. B. Kokta, J. Appl. Polym. Sci., 40, 917 (1990).

14. D. Maldas and B. V. Kokta, J. Appl. Polym. Sci., 41, 185 (1990).

15. N. G. Gaylord, U.S. Patent, 3645939 (February 29, 1972).

16. H. Kishi, M. Yoshioka, A. Yamanoi, and N. Shiraishi, J. Jpn. Wood Res. Soc., 34, 133 (1988).

17. G. S. Han, H. Ichinose, S. Takase, and N. Shiraishi, J. Jpn. Wood Res. Soc., 35, 1100 (1989).

18. D. Maldas and B. V. Kokta, Intern. J. Polymeric Mater., 14, 165 (1990).

19. S. Takase and N. Shiraishi, J. Appl. Polym. Sci., 37, 645 (1989).

20. A. A. Pohlman and M. S. Dissertation, University of California, Berkeley, 1974.

21. R. L. Pastorino, R. N. Lewis, and R. Halle, Modern Plast. Encycl., 62(10A), 159 (1985-1986).

22. P. A. Callais and R. T. Kazmierczak, Proceedings, SPE Antec 89, May 1989, p 1368.

23. J. A. Clark, "Pulp Technology and Treatment for Paper," 2nd ed., Miller Freeman Publications, Inc., San Francisco, 1985, Chapter 9, p 184.

24. B. V. Kokta, J. L. Valade, and C. Daneault, Pulp and Paper Canada, Transactions, TR 59 (September, 1979).

25. D. Maldas, B. V. Kokta, and C. Daneault, J. Appl. Polym. Sci., 38, 413 (1989).

26. D. K. Setua, "Polymer Science and Technology," Vol. 33, C. E. Carraher and L. H. Sperling Ed., Plenum Press, New York, N.Y., 1986, p 275. 